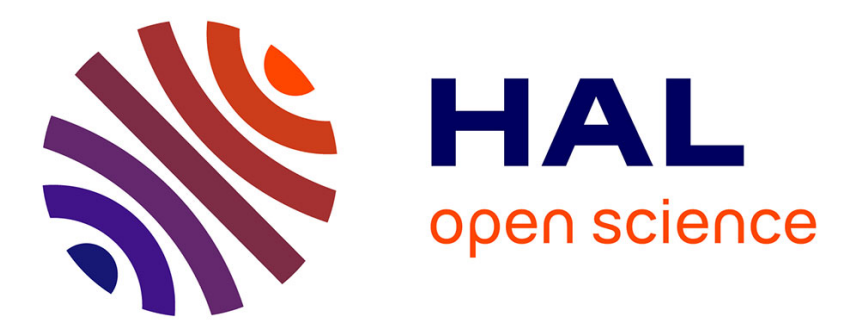

\title{
Copper and nickel removal from aqueous solutions using functionalized polyacrylonitrile fibers: equilibrium, kinetic, and thermodynamic studies
}

\author{
Hayat Bouchoum, Fatine Akoh, Mehdi El Bouchti, Amane Jada, Mohamed \\ Tahiri, Omar Cherkaoui
}

\section{To cite this version:}

Hayat Bouchoum, Fatine Akoh, Mehdi El Bouchti, Amane Jada, Mohamed Tahiri, et al.. Copper and nickel removal from aqueous solutions using functionalized polyacrylonitrile fibers: equilibrium, kinetic, and thermodynamic studies. Desalination and Water Treatment, 2020, 204, pp.213-223. 10.5004/dwt.2020.26260 . hal-03042599

\section{HAL Id: hal-03042599 \\ https://hal.science/hal-03042599}

Submitted on 6 Dec 2020

HAL is a multi-disciplinary open access archive for the deposit and dissemination of scientific research documents, whether they are published or not. The documents may come from teaching and research institutions in France or abroad, or from public or private research centers.
L'archive ouverte pluridisciplinaire HAL, est destinée au dépôt et à la diffusion de documents scientifiques de niveau recherche, publiés ou non, émanant des établissements d'enseignement et de recherche français ou étrangers, des laboratoires publics ou privés.

$$
\text { Copyright }
$$




\title{
Copper and nickel removal from aqueous solutions using functionalized polyacrylonitrile fibers: equilibrium, kinetic, and thermodynamic studies
}

\author{
Hayat Bouchoum ${ }^{\mathrm{a}, \mathrm{b}}$, Fatine Akoh ${ }^{\mathrm{a}, \mathrm{b}}$, Mehdi El Bouchti ${ }^{\mathrm{b}}$, Amane Jada ${ }^{\mathrm{c}, \mathrm{d}, *}$, \\ Mohamed Tahiri, , Omar Cherkaoui ${ }^{\mathrm{b}}$ \\ ${ }^{a}$ Laboratory of Geosciences, Geology department, Hassan II University, Casablanca, Morocco, \\ emails: bouchoum.hayat@gmail.com (H. Bouchoum), akoh.fatine@gmail.com (F. Akoh), mohtahiri@yahoo.fr (M. Tahiri) \\ ${ }^{b}$ REMTEX Laboratory, Higher school of textile and clothing industry, Casablanca, Morocco, emails: melbouchti@gmail.com (M. El Bouchti), \\ omarcherkaoui61@gmail.com (O. Cherkaoui) \\ 'Institut des Sciences des Matériaux de Mulhouse, IS2M-CNRS, Université de Haute Alsace, Mulhouse, France, \\ email: amane.jada@uha.fr (A.Jada) \\ 'Université de Strasbourg, Strasbourg, France
}

Received 4 February 2020; Accepted 13 June 2020

\section{A B S T R A C T}

Amidoximated polyacrylonitrile fibers (AO-PANF) were prepared from the pristine PANF by using hydroxylamine as chelating agent. Thereafter, the AO-PANF was used as adsorbent for removing toxic metals such as copper and nickel from aqueous solutions. Further, the effects of various adsorption parameters, affecting the metal removal from water, such as the aqueous phase $\mathrm{pH}$, the contact time adsorbate-adsorbent, the adsorbent dose, and the temperature, were assessed. The overall data indicate that metal removal from water increases with increasing the magnitude of these adsorption parameters. Furthermore, to evaluate the theoretical trends of the metal adsorption from water onto the AO-PANF adsorbent, the experimental adsorption data were compared to the kinetic and equilibrium theoretical models. Thus, at the equilibrium, a good agreement was found between the data and the Langmuir model, whereas the kinetics results were found to follow the pseudo-second-order. The results have also showed that by using the Langmuir model equation, the obtained adsorption capacities for copper and nickel were 11.56 and $6.87 \mathrm{mg} \mathrm{g}^{-1}$, respectively. Finally, the thermodynamic investigations indicate that the adsorption was spontaneous and endothermic. The overall data shown in the present work indicate that functionalized polyacrylonitrile fibers, AO-PANF, are efficient adsorbent for the copper and the nickel removal from water.

Keywords: Environmental chemistry; Water treatment; Amidoxime; Polyacrylonitrile; Heavy metal

\section{Introduction}

Wastewater containing heavy metals have attracted widespread interest due to their negative effect on human health and ecosystems [1]. Copper and nickel are widely used in various industries such as mining, oil refinery, batteries, textile, and electroplating industries [2]. These metals were classified by the United States Environmental Protection Agency (EPA) as priority pollutants $[3,4]$ and tend to accumulate in the organisms through water, food chain, and blood due to their high solubility and non-biodegradability nature [5]. Copper and nickel, at levels traces, are considered

* Corresponding author. 
an essential micro-nutrient to humans and other living species [6-8]. However, when human is exposed to high metal concentrations, it will result in irritation, diarrhea, mental and neurological diseases, memory loss, cancer, and liver damage [6,9]. According to the United States Environmental Protection Agency (EPA), the maximum copper and nickel concentrations permissible in industrial effluents are, respectively, 1.3 and $0.9 \mathrm{mg} \mathrm{L}^{-1}[10,11]$. The human life toxicity of these two metals and the ecosystem alteration, underline the necessity to remove them from the polluted effluents. Up to now, various treatment methods including, chemical precipitation, electrocoagulation, adsorption, ion exchange, reverse osmosis, nano, and ultra-filtration have been used to remove heavy metals from aqueous solutions [12]. Adsorption technology is considered to be the most effective and economical method to remove copper and nickel from the polluted aqueous solutions $[13,14]$. The advantages of this method are summed up in its simplicity, speed, lowcost process, no sludge production, good stability, reusability, and the ability to remove trace metals ions $[1,15]$. The adsorption efficiency depends mainly on the nature of the adsorbents used to remove pollutants from aqueous solutions [16]. Commonly, activated carbon, powder or granular forms, were the most adsorbents used to remove heavy metals from aqueous solutions. However, the main drawbacks of these adsorbents are the high-cost production, the complicated pre-treatment [9,17]. Therefore, it is necessary to look for an adsorbent able to remove effectively heavy metals from aqueous while being simple chemically and low cost economically. The use of polymeric materials as an adsorbent has demonstrated its effectiveness to remove heavy metals from aqueous solutions. Among them, polyacrylonitrile are the most polymeric materials used. It is a commercial and low-cost polymers materials having good mechanical, chemical, thermal stability and good resistance to corrosion and solvent [18]. Polyacrylonitrile contain hydroxyl $(\mathrm{OH})$ and amino $\left(\mathrm{NH}_{2}\right)$ groups in their backbone, making it a good adsorbent for water purification, heavy metals and dyes removal from aqueous solutions [19]. Chemical modification of polyacrylonitrile surface with various chemical reactants such as hydroxylamine, diethylenediamine [20], ethylenediamine, triethylenetetramine [21], carboxyl, imidazole [18], will improve its adsorptive property and then will enhance the removal efficiency of the pollutants from water. It should be noted that hydroxylamine is a promoting chelating agent, containing nitrogen and oxygen atoms, which have a strong affinity toward heavy metals ions. Further, the nitrile groups present on the polyacrylonitrile surface can be easily transformed onto a variety of functional groups such as carboxyl, amine, amidoxime, phosphoric, etc. Amidoxime group contains a combination of $=\mathrm{NOH}$ and $\mathrm{NH}_{2}$ functional groups which can separate and recover heavy metals from solutions through the chelation process [22]. Regarding the use of polyacrylonitrile in different physical forms, many studies have concerned its capacity to remove copper and nickel from aqueous solutions. Zeng et al. [23], prepared an amidoxime adsorbent by grafting acrylonitrile onto natural loofah sponge, and reacted with hydroxylamine hydrochloride subsequently. In that reported work, the amidoxime-modified poly (AN-gloofah) showed that the $\mathrm{Cu}^{2+}$ adsorption capacity reached
$51.40 \mathrm{mg} \mathrm{g}^{-1}$. Further, Abdouss et al. [20] have prepared polyacrylonitrile fibers (PANF) by electro spinning technique to be used in copper removal from aqueous solutions. The modification of the electro spun PANF was made by using 3.2 $\mathrm{M}$ of diethylenetriamine (DETA) chelating agents for $8 \mathrm{~h}$ at $92^{\circ} \mathrm{C}$. According to Abdouss et al. [20] reported work, the achieved adsorption capacity of copper from water onto the modified PANF was $7 \mathrm{mg} \mathrm{g}^{-1}$. Another investigation was carried out by using electro spun polyacrylonitrile nanofiber modified with imidazole ligand at a concentration range of $0.15-1 \mathrm{M}$, for nickel removal from aqueous solutions. In this reported work, the conversion of nitrile groups has attained $36 \%$ for a reaction time of $1 \mathrm{~h}$, and the adsorption capacity reached $0.8 \mathrm{~mol} \mathrm{Kg}^{-1}$ at $\mathrm{pH} 5$ [18]. Several methods were used to prepare amidoximated polyacrylonitrile fibers using a considerable amount of chemical products including the chelating agents. However, in developing countries, the process cost is an important decision factor. In addition, a low-cost process with a simple feasible method, saving energy, time, products, and at the same time being effective, is attractive for industrial utilization. At the same time, using polyacrylonitrile as fiber is effective for metal removal from aqueous solutions owing to their large surface area and a short diffusion rate [20]. Moreover, the removal of $\mathrm{Cu}^{2+}$ and $\mathrm{Ni}^{2+}$ was mainly carried out for high initial concentrations up to $2,000 \mathrm{mg} \mathrm{L}^{-1}$, whereas the removal with lower concentrations was weakly discussed. Based on that, in a previous study, we synthesized AO-PANF using a straightforward and cheap method with a minimum condition of the modification, which is also realizable in industry. The removal capacity of $\mathrm{Cr}(\mathrm{VI})$ was evaluated. The achieved conversion of nitrile groups was $33.7 \%$ by using $0.15 \mathrm{M}$ of $\mathrm{NH}_{2} \mathrm{OH}$ for a reaction time of $1 \mathrm{~h}$ at reaction temperature $T=70^{\circ} \mathrm{C}$. The synthesized adsorbent has demonstrated good performance for $\mathrm{Cr}(\mathrm{VI})$ removal from aqueous solutions with an adsorption capacity of $32.57 \mathrm{mg} \mathrm{g}^{-1}$. The Fourier transform infrared (FTIR) and scanning electron microscopy (SEM) analyzes were performed and have confirmed the conversion of nitrile groups.

Others researches have confirmed the ability of AO-PANF to remove $\mathrm{Cr}(\mathrm{VI})$ from aqueous solutions. Hence, Avila et al. [24] have prepared AO-PAN nanofibers to confirm the ability of amine and oxime groups of amidoximes to remove $\mathrm{Cr}(\mathrm{VI})$ from aqueous solutions. According to these authors, the maximum adsorption capacity was $156 \mathrm{mg} \mathrm{g}^{-1}$, with a desorption percentage of $90 \%$. However, in the work of Avila et al. [24], the preparation of the adsorbent was made by using DMF chemical product, and an electro spinning technique, which increases both the production cost and the environmental damage.

In the present work, the amidoximated polyacrylonitrile fibers (AO-PANF) were prepared and used in order to investigate their capacity to remove other heavy metals such $\mathrm{Cu}$ (II) and $\mathrm{Ni}$ (II) from aqueous solutions. The effects of adsorption parameters on the AO-PANF adsorption capacity were assessed. Furthermore, kinetics and isotherm studies were evaluated by comparing the experimental data to some equation's models. After adsorption process, the AO-PANF was tested for desorption and regeneration. The effects of co-existing ions in the aqueous solution, on the adsorption capacities of $\mathrm{Cu}(\mathrm{II})$ and $\mathrm{Ni}(\mathrm{II})$, were also evaluated. 


\section{Experimental section}

\subsection{Material and methods}

Commercial polyacrylonitrile fibers (PANF) was cut, washed with distillated water, and then dried in an oven. Hydroxylamine hydrochloride, with a purity $>99 \%$, was purchased from Scharlab, whereas chemical salts, such as $\mathrm{CuSO}_{4} \cdot 5 \mathrm{H}_{2} \mathrm{O}$ and $\mathrm{NiCl}_{2} \cdot 6 \mathrm{H}_{2} \mathrm{O}$, with purities of $97 \%$ and $99 \%$, respectively, were obtained from Sigma-Aldrich (SaintLouis, Missouri, United States). Sodium hydroxide ( $\mathrm{NaOH}$, $\left.0.1 \mathrm{~mol} \mathrm{~L}^{-1}\right)$ and hydrochloric acid, $\left(\mathrm{HCl}, 0.1 \mathrm{~mol} \mathrm{~L}^{-1}\right)$ aqueous solutions, were used to adjust the aqueous phase $\mathrm{pH}$, which was measured, by using a $\mathrm{pH}$ meter Thermo Scientific (Waltham, Massachusetts, United States) Orion 4 STAR. The metal solutions were prepared by diluting $1 \mathrm{~g} \mathrm{~L}^{-1}$ of $\mathrm{CuSO}_{4} \cdot 5 \mathrm{H}_{2} \mathrm{O}$, and $\mathrm{NiCl}_{2} \cdot 6 \mathrm{H}_{2} \mathrm{O}$, with distillated water desired amounts. The residual concentrations of $\mathrm{Cu}(\mathrm{II})$ and $\mathrm{Ni}(\mathrm{II})$ were assessed by using complexometric titration and murexide as indicator. Chemical salts such as potassium dichromate $\left(\mathrm{K}_{2} \mathrm{Cr}_{2} \mathrm{O}_{7}\right)$, sodium sulfate $\left(\mathrm{Na}_{2} \mathrm{SO}_{4}\right)$, and sodium phosphate $\left(\mathrm{Na}_{3} \mathrm{PO}_{4}\right)$ were used to prepare $\mathrm{Cr}, \mathrm{SO}_{4^{\prime}}$ and $\mathrm{PO}_{4}$ aqueous solutions. The residual concentrations of these elements were determined using Thermo-Fisher (Waltham, Massachusetts, United States) Evolution ${ }^{\mathrm{TM}} 300 \mathrm{UV}$-vis spectrophotometer, at room temperature.

\subsection{PANF surface modification}

The surface modification of PANF by one-step reaction was done according to the procedure described in our previous work as illustrated in Fig. 1 [25].

In the previous work, we synthesized an adsorbent, called "AO-PANF" for heavy metal removal, by converting the nitrile groups containing on the polyacrylonitrile fibers onto amidoximes groups. Such synthesis was carried out taking into account the production cost and the used chemical additive natures. Hydroxylamine hydrochloride was added to a flask containing both PANF and $\mathrm{NaOH}$ solutions (methanol/water 5:1). The methanol was added to $\mathrm{NaOH}$ solution to dissolve hydroxylamine hydrochloride and to obtain a homogenous solution for the amidoximation reaction. After the treatment, the adsorbent was separated from the solution by filtration, washed several times with a mixed methanol/water solution, and finally dried in oven for $1 \mathrm{~d}$ at $60^{\circ} \mathrm{C}$. The modified PANF obtained by using $0.15 \mathrm{M}$ of hydroxylamine for $60 \mathrm{~min}$, at reaction temperature $T=70^{\circ} \mathrm{C}$, was found to produce high conversion rate of nitrile groups of $33.7 \%$ and to have acceptable mechanical properties. Note that the PANF color was changed from white to yellow after modification. As in our previous work, methods such as FTIR spectroscopy and SEM were used to characterize the PANF and AO-PANF samples. These techniques, of the AO-PANF characterization, were used by others researchers to confirm the modification process $[24,26]$.

\subsection{Copper and nickel removals from water onto AO-PANF}

$\mathrm{Cu}(\mathrm{II})$ and $\mathrm{Ni}(\mathrm{II})$ solutions were prepared by dissolving defined quantities of $\mathrm{CuSO}_{4} \cdot 5 \mathrm{H}_{2} \mathrm{O}$ and $\mathrm{NiCl}_{2} \cdot 6 \mathrm{H}_{2} \mathrm{O}$ in distillated water. The adsorption experiments were investigated by making contacts of the AO-PANF samples with $50 \mathrm{~mL}$ of the aqueous metal solutions at given concentrations ( $30 \mathrm{mg} \mathrm{L}^{-1}$ ) and by shaking the resulted mixtures at room temperature for contact time intervals of $60 \mathrm{~min}$. Thereafter, for each mixture, the adsorbent was separated from the supernatant by filtration, washed with distillated water to remove the non-adsorbed metal and finally dried in an oven. The residual concentrations of $\mathrm{Cu}(\mathrm{II})$ and $\mathrm{Ni}$ (II) in the supernatant were determined by complexometric titration using ethylenediaminetetraacetic (EDTA) with murexide as indicator $[27,28]$. The titration method, compared with quantitative instrumental measurements such inductively

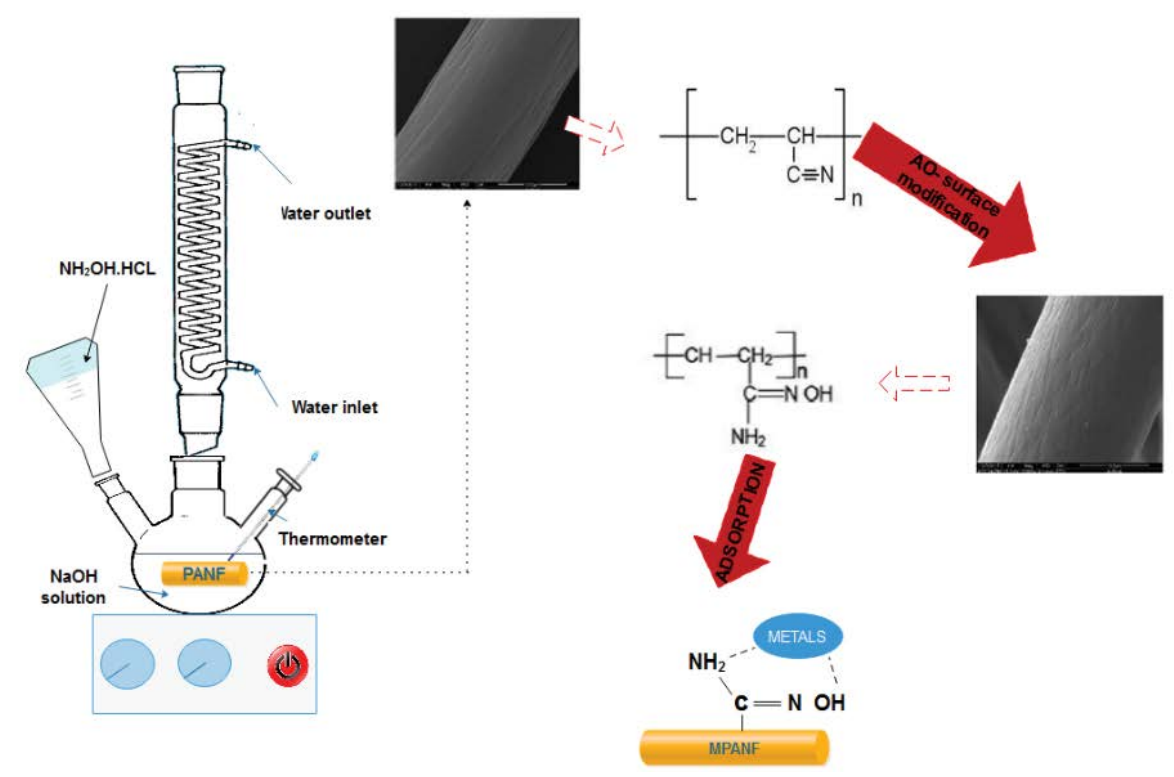

Fig. 1. Schematic illustration of the experimental surface modification of PANF with hydroxylamine, and metal adsorption process from water onto AO-PANF. 
coupled plasma mass spectrometry or atomic absorption spectroscopy, is more accurate, sensitive and simple for the rapid and quantitative chemical analysis for metal ions [29]. The complexometric titration using EDTA as a chelator is a well-known analytical technique. In this study, the effect of adsorption parameters such as $\mathrm{pH}$ solution, contact time, temperature, initial concentration, and adsorbent dose on the adsorption capacity, were investigated. The method and the conditions will be mentioned in each part of the adsorption parameter study. The effect, of coexisting ions on the adsorption study, was investigated in this paper. The method and technique used will be described in the subsequent sections.

Triplicate experiments were carried out for all adsorption parameters. The adsorption capacity $\left(\mathrm{mg} \mathrm{g}^{-1}\right)$ was calculated using Eq. (1):

$q_{e}=V \times\left[\frac{\left(C_{0}-C_{1}\right)}{W}\right]$

where $q_{e}$ is the equilibrium adsorption capacity $\left(\mathrm{mg} \mathrm{g}^{-1}\right), C_{0}$ and $C_{1}$ are, respectively, the initial and the final concentrations of $\mathrm{Cu}(\mathrm{II})$ and $\mathrm{Ni}(\mathrm{II})\left(\mathrm{mg} \mathrm{L}^{-1}\right), V$ is the volume of solution (L), and $W$ is the adsorbent weight $(\mathrm{g})$.

The reuse of AO-PANF was firstly investigated using $20 \mathrm{~mL}$ of $0.1 \mathrm{M}$ of $\mathrm{HCl}$, at $25^{\circ} \mathrm{C}$, for $1 \mathrm{~h}$ in order to test the desorption efficiency. After the desorption process, the AO-PANF was washed with distillated water and prepared for the next adsorption-desorption cycle.

\subsubsection{Kinetic adsorption models}

In the present work, the adsorption kinetic models include the pseudo-first-order [Eq. (2)], the pseudo-secondorder [Eq. (3)], the intra-particle diffusion [Eq. (4)]), and the Elovich model [Eq. (5)].

$\log \left(q_{e}-q_{t}\right)=\log q_{e}-k_{1} t$

$\frac{t}{q_{t}}=\frac{1}{k_{2} q_{e}^{2}}+\frac{t}{q_{e}}$

$q_{t}=k_{\mathrm{id}} t^{1 / 2}+C$

$q_{t}=\frac{1}{2} \ln (\alpha \beta)+\frac{1}{\beta} \ln (t)$

where $q_{e}$ and $q_{t}$ are the adsorption capacities at equilibrium and at time $(t)$, respectively, expressed in $\mathrm{mg} \mathrm{g}^{-1}$. The term $k_{1}$ is the pseudo-first-order rate constant $\left(\mathrm{min}^{-1}\right) . k_{2}$ is the pseudo-second-order rate constant $\left(\mathrm{g} \mathrm{mg}^{-1} \mathrm{~min}^{-1}\right)$. Where $k_{\mathrm{id}}$ is the intra-particle diffusion model constant $\left(\mathrm{mg} \mathrm{g}^{-1} \mathrm{~min}^{-1 / 2}\right)$, and $C$ is the boundary thickness $\alpha$ and $\beta$ are, respectively, the initial adsorption rate expressed in $\left(\mathrm{mg} \mathrm{g}^{-1} \mathrm{~min}^{-1}\right)$, and the desorption constant expressed in $\left(\mathrm{g} \mathrm{mg}^{-1}\right)$, and related to the surface coverage and the activation energy.

\subsubsection{Equilibrium adsorption models}

Langmuir [Eq. (6)], Freundlich [Eq. (7)], and DubininRadushkevich [Eq. (8)] models were used to discuss the adsorption capacity of the adsorbent and describe the interaction between the pollutant and the adsorbent.

$\frac{C_{e}}{q_{e}}=\frac{C_{e}}{q_{m}}+\frac{1}{K_{L} q_{m}}$

$\log q_{e}=\log K_{F}+\frac{1}{n} \log C_{e}$

$\ln q_{e}=\ln q_{m}-B \varepsilon^{2}$

where $\varepsilon$, is the Polanyi potential $\left(\mathrm{J}^{2} \mathrm{~mol}^{-2}\right)$

$\varepsilon=R T \ln \left[1+\frac{1}{C_{e}}\right]$

where $C_{e}$ is the equilibrium concentration of the metal in the solution $\left(\mathrm{mg} \mathrm{L}^{-1}\right), q_{e}$ is the amount of metal adsorbed onto AO-PANF at equilibrium $\left(\mathrm{mg} \mathrm{g}^{-1}\right), q_{m}$ is the maximum adsorption capability $\left(\mathrm{mg} \mathrm{g}^{-1}\right)$ and $K_{L}$ is the Langmuir constant $\left(\mathrm{L} \mathrm{mg}^{-1}\right) . K_{F}\left[\left(\mathrm{mg} \mathrm{g}^{-1}\right)\left(\mathrm{L} \mathrm{mg}^{-1}\right)^{1 / n}\right]$ and the exponent $(1 / n)$ are the Freundlich constants representing the adsorption capacity and the intensity of adsorption, respectively. $B$, in the Dubinin-Radushkevich equations, is a constant associated with the adsorption energy.

\section{Results and discussions}

\subsection{Effect of aqueous solution initial $p H$}

The initial $\mathrm{pH}$ of the aqueous solution is an important parameter affecting the surface charge of the adsorbent and the metal speciation. The $\mathrm{pH}$ effect on the AO-PANF adsorption capacity was investigated by varying the aqueous solution initial $\mathrm{pH}$, from 2.0 to 6.0 for $\mathrm{Cu}$ (II) and from 2.0 to 8.0 for $\mathrm{Ni}$ (II) (Fig. 2).

The $\mathrm{pH}$ effect was investigated at room temperature, by mixing an amount of a metallic solution having initial concentration of $25 \mathrm{mg} \mathrm{L}^{-1}$, with $0.1 \mathrm{~g}$ of the adsorbent, for a period time of $60 \mathrm{~min}$. We choose to work at this $\mathrm{pH}$ interval to prevent any precipitations of metal hydroxides.

As can be seen in Fig. 2, for $\mathrm{Cu}(\mathrm{II})$ and $\mathrm{Ni}(\mathrm{II})$, the removal efficiency $(R)$ increases with increasing aqueous solution initial $\mathrm{pH}$ to reach an adsorption capacities of $9.39 \mathrm{mg} \mathrm{g}^{-1}$ $(R=75.79 \%)$ at $\mathrm{pH}=5.0$ and $2.66 \mathrm{mg} \mathrm{g}^{-1}(R=56.79 \%)$ at $\mathrm{pH}=7$, respectively, which are consistent with previous reported works $[9,30,31]$.

In fact, with an $\mathrm{pH}_{\mathrm{pzc}}$ of $\mathrm{AO}-\mathrm{PANF}=3.9$, when the aqueous solution initial $\mathrm{pH}$ is $<\mathrm{pH}_{\mathrm{pzc}^{\prime}}$ the adsorbent charge is positively charged due to the high concentration of hydronium ions $\left(\mathrm{H}_{3} \mathrm{O}^{+}, \mathrm{H}^{+}\right)$, leading to an electrostatic repulsion occurring between the positively charged metal ions present in solution, and the positively charged AO-PANF, and resulting in low adsorption capacity. However, an increase in solution $\mathrm{pH}$ at $\mathrm{pH}>\mathrm{pH}_{\mathrm{pzc}}$ leads to negatively 


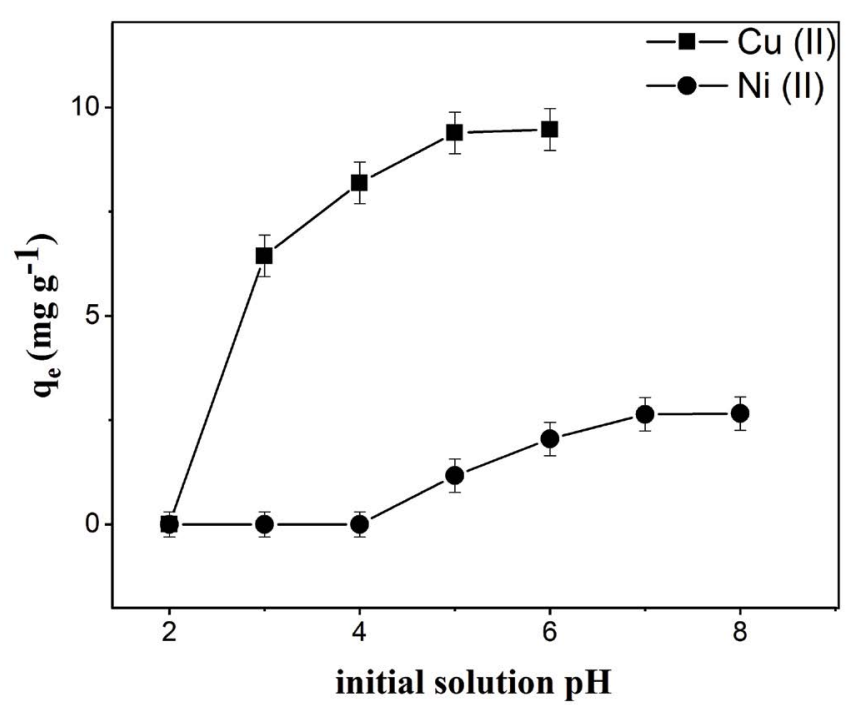

Fig. 2. Effect of initial solution $\mathrm{pH}$ on adsorption capacity of $\mathrm{Cu}(\mathrm{II})$ and $\mathrm{Ni}(\mathrm{II})$ from aqueous solutions.

charged adsorbent surface due the deprotonation of the solid functional groups, and generate an increase in the adsorption capacity, as resulting from an electrostatic attraction between the negatively charged AO-PANF and the positively charged metals ions $\left(\mathrm{Cu}^{2+}, \mathrm{Cu}(\mathrm{OH})^{+}\right.$, and $\left.\mathrm{Ni}^{2+}\right)[32,33]$. Therefore, the following experiments will be performed at $\mathrm{pH}=5$ and at $\mathrm{pH}=7$ for $\mathrm{Cu}(\mathrm{II})$ and $\mathrm{Ni}(\mathrm{II})$, respectively.

\subsection{Effect of the contact time adsorbent-adsorbate}

The effect of the contact time of the AO-PANF and the divalent cations, on the adsorption capacity was studied using a constant initial metal concentration of $30 \mathrm{mg} \mathrm{L}^{-1}$ for $\mathrm{Cu}(\mathrm{II})$ and $\mathrm{Ni}(\mathrm{II})$, at $\mathrm{pH}=5$ and 7 , respectively. Thus, the obtained adsorption data for a various contact times varying in the range 10-120 min, are represented in Fig. 3.

As can be seen in this figure, the adsorption capacity increases with increasing contact time and leveled out, at 90 and $30 \mathrm{~min}$, for $\mathrm{Cu}(\mathrm{II})$ and $\mathrm{Ni}(\mathrm{II})$, respectively. In case of $\mathrm{Ni}(\mathrm{II})$, the adsorption shows an abrupt jump in the 1st min and quickly reaches the equilibrium plateau. These results demonstrated that the adsorption onto AO-PANF takes place on the external surface on which there is no need to reach the equilibrium for a longer contact time [1]. Therefore, the optimal contact time of 90 and $30 \mathrm{~min}$ for $\mathrm{Cu}(\mathrm{II})$ and $\mathrm{Ni}(\mathrm{II})$, respectively, were selected for further experiments.

\subsection{Adsorbent dosage effect}

The removal efficiency of AO-PANF toward $\mathrm{Cu}(\mathrm{II})$ (10 $\left.\mathrm{mg} \mathrm{L}^{-1}\right)$ and $\mathrm{Ni}(\mathrm{II})\left(25 \mathrm{mg} \mathrm{L}^{-1}\right)$, were studied separately by varying the adsorbent weight from 0.02 to $0.4 \mathrm{~g}$, and the data are presented in Fig. 4.

Note that the optimization of adsorbent dose allows the utilization of the full adsorbent surface. As shown in Fig. 4, increases of the adsorption capacities from 3.46 to $4.16 \mathrm{mg} \mathrm{g}^{-1}$ for $\mathrm{Cu}(\mathrm{II})$ and from 0.84 to $2.07 \mathrm{mg} \mathrm{g}^{-1}$ for

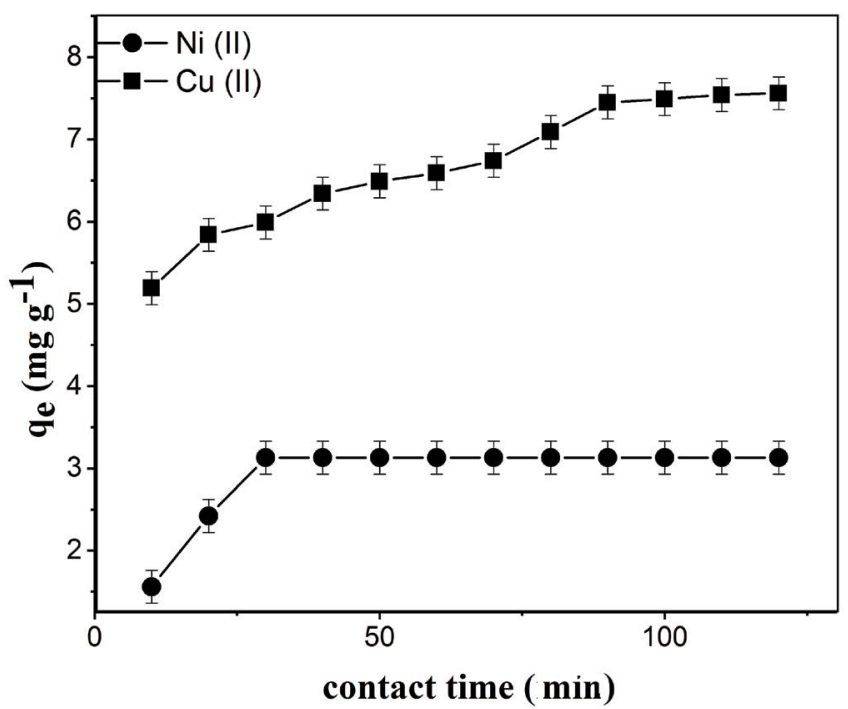

Fig. 3. Effect of contact time on $\mathrm{Cu}(\mathrm{II})$ and $\mathrm{Ni}(\mathrm{II})$ adsorption capacity from aqueous solutions.

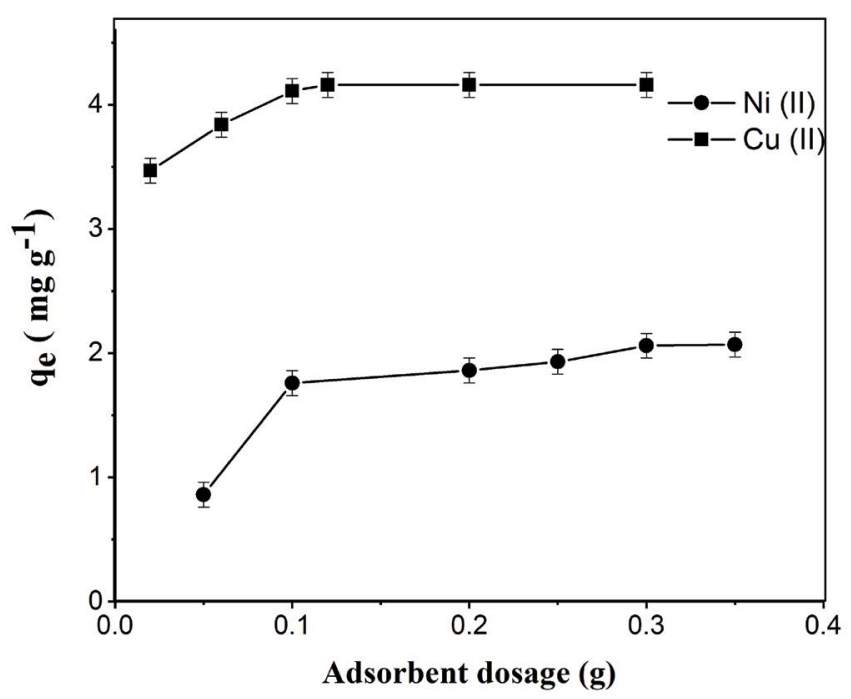

Fig. 4. Effect of adsorbent dose on the $\mathrm{Cu}(\mathrm{II})$ and $\mathrm{Ni}(\mathrm{II})$ adsorption capacity from aqueous solutions onto the AO-PANF.

$\mathrm{Ni}(\mathrm{II})$ are observed, with increasing the adsorbent dosage. In the case of $\mathrm{Cu}(\mathrm{II})$, no removal increase was obtained after reaching $0.1 \mathrm{~g}$ of the adsorbent dose, while for $\mathrm{Ni}(\mathrm{II})$ adsorption needs more adsorbent amount $(0.3 \mathrm{~g})$ to reach the equilibrium. It is noteworthy that an increase in adsorbent weight provides more AO-PANF surface sites which enhance the heavy metals removal efficiency [30]. A rapid adsorption of $\mathrm{Cu}$ (II) compared to $\mathrm{Ni}$ (II) from water onto the AO-PANF surface demonstrated that the adsorbent has more affinity towards $\mathrm{Cu}(\mathrm{II})$ as compared to $\mathrm{Ni}$ (II) ions. The results analyses have shown that the optimal adsorbent dose for $\mathrm{Cu}(\mathrm{II})$ and $\mathrm{Ni}(\mathrm{II})$, are, 0.1 and $0.3 \mathrm{~g}$, respectively. Therefore, in the following experiments only the optimal adsorbent doses will be used. 


\subsection{Temperature effect and thermodynamic studies}

The effect of temperature on the adsorption was investigated by varying the temperature, from $T=10^{\circ} \mathrm{C}$ to $65^{\circ} \mathrm{C}$ while keeping the others parameters constants. Fig. 5 shows that for $\mathrm{Cu}(\mathrm{II})$, the adsorption capacity increases from 2.20 to $9.02 \mathrm{mg} \mathrm{g}^{-1}$ with increasing temperature up to $T=30^{\circ} \mathrm{C}$, and thereafter the adsorption is slowed.

In case of $\mathrm{Ni}(\mathrm{II})$, the adsorption increases from 1.51 to $2.7 \mathrm{mg} \mathrm{g}^{-1}$ with increasing temperature up to $30^{\circ} \mathrm{C}$ and it levels out thereafter. The increase in adsorption capacity with increasing the temperature indicates an endothermic adsorption process. A similar temperature effect was also observed in previous reported work dealing with the adsorption of $\mathrm{Cr}(\mathrm{VI})$ from water onto AO-PANF surface, which was also endothermic. From Fig. 5, we can see that the adsorption capacity of $\mathrm{Cu}(\mathrm{II})$ increases sharply with temperature while the adsorption capacity of $\mathrm{Ni}(\mathrm{II})$ is experiencing a slight increase before becoming constant. This is due to the full occupation of actives sites of AO-PANF with the temperature increase [34]. Our results are in agreement with previous works carried out by other authors [34]. Here, we find that the optimal temperature for maximum adsorption capacity is $T=30^{\circ} \mathrm{C}$. Thereafter, after $30^{\circ} \mathrm{C}$, no significant change was observed in the adsorption capacity of metals. This is why we choose to perform adsorption experiments at room temperature in order to avoid energy consumption. The thermodynamic parameters including Gibbs free energy $\Delta G^{\circ}\left(\mathrm{KJ} \mathrm{mol}^{-1}\right)$, entropy change $\Delta S^{\circ}\left(\mathrm{J} \mathrm{K}^{-1} \mathrm{~mol}^{-1}\right)$, and enthalpy change $\Delta H^{\circ}\left(\mathrm{KJ} \mathrm{mol}^{-1}\right)$, were calculated using Van't Hoff equation and are gathered in Table 1.

$\Delta G=-R T \ln K_{d}$

$\ln K_{d}=-\frac{\Delta H}{R T}+\frac{\Delta S}{R}$

where $K_{d}$ is the equilibrium constant, $R$ is the gas constant $\left(8.314 \mathrm{~J} \mathrm{~mol}^{-1} \mathrm{~K}^{-1}\right)$, and $T$ is the Kelvin temperature.

Note that the values of $\Delta H^{\circ}$ and $\Delta S^{\circ}$ were determined from the plot of $\ln K_{d}$ vs. $1 / T$.

According to Table 1 , the negative values of $\Delta G^{\circ}$ indicate the spontaneity of the process for the removal of $\mathrm{Cu}(\mathrm{II})$ and $\mathrm{Ni}(\mathrm{II})$ ions from aqueous solutions. As well, the increase of temperature decreases the $\Delta G^{\circ}$ values, which demonstrated that the adsorption is effective and spontaneous at higher temperature values. The calculated $\Delta G^{\circ}$ values are more negative for $\mathrm{Cu}(\mathrm{II})$ as compared to $\mathrm{Ni}(\mathrm{II})$ ions, suggesting hence that the adsorption of $\mathrm{Cu}(\mathrm{II})$ is more feasible on the adsorbent surface. The $\Delta H^{\circ}$ values of both $\mathrm{Cu}(\mathrm{II})$ and $\mathrm{Ni}(\mathrm{II})$ are found between -20 and $-40 \mathrm{KJ} \mathrm{mol}^{-1}$, indicating a physical adsorption process [30]. Also, the positive values of $\Delta S^{\circ}$ and $\Delta H^{\circ}$ confirms the randomness and endothermic process for $\mathrm{Cu}(\mathrm{II})$ and $\mathrm{Ni}(\mathrm{II})$ adsorption onto AO-PANF [1]. However, from kinetics study, we found that the adsorption of $\mathrm{Cu}(\mathrm{II})$ and $\mathrm{Ni}(\mathrm{II})$ was chemical in nature. From these results, we can said that the adsorption of metals onto AO-PANF followed a physico-chemical process [35].

\subsection{Kinetics adsorption modeling}

The modeling of the kinetic adsorption of $\mathrm{Cu}(\mathrm{II})$ and $\mathrm{Ni}(\mathrm{II})$ onto AO-PANF were performed by using pseudofirst-order, pseudo-second-order, intra-particle, and Elovich models. For all kinetics adsorption models, the equations were applied for the adsorption period ranging from 10 to $120 \mathrm{~min}$. The modeling results are presented in Fig. 6 and summarized in Table 2.

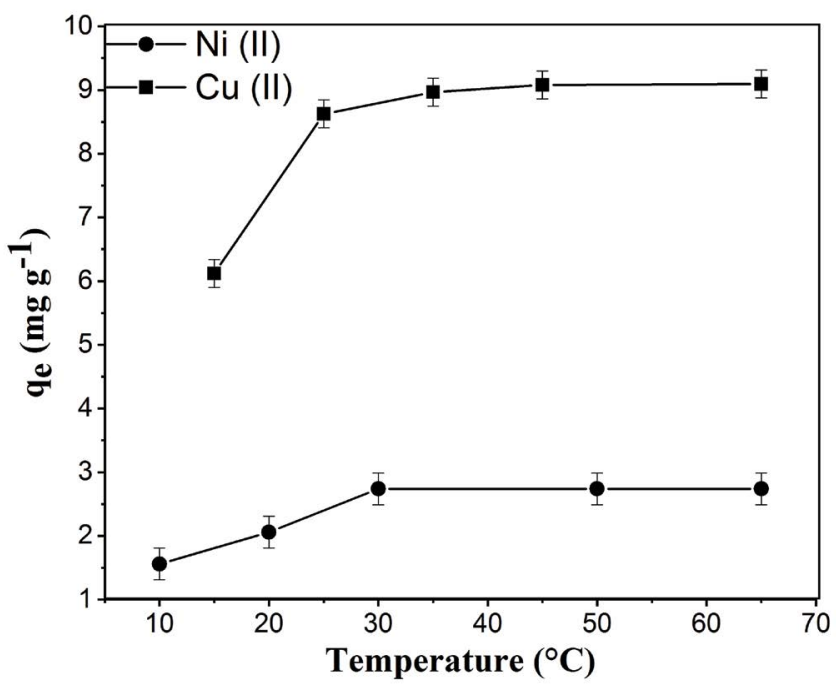

Fig. 5. Effect of temperature on $\mathrm{Cu}(\mathrm{II})$ and $\mathrm{Ni}(\mathrm{II})$ adsorption capacity from aqueous solutions.

Table 1

Thermodynamic parameters of $\mathrm{Cu}(\mathrm{II})$ and $\mathrm{Ni}(\mathrm{II})$ adsorption

\begin{tabular}{|c|c|c|c|c|c|c|}
\hline \multirow[b]{2}{*}{$T\left({ }^{\circ} \mathrm{K}\right)$} & \multicolumn{3}{|c|}{$\mathrm{Cu}(\mathrm{II})$} & \multicolumn{3}{|c|}{$\mathrm{Ni}(\mathrm{II})$} \\
\hline & $\Delta G^{\circ}\left(\mathrm{KJ} \mathrm{mol}^{-1}\right)$ & $\Delta S^{\circ}\left(\mathrm{J} \mathrm{K}^{-1} \mathrm{~mol}^{-1}\right)$ & $\Delta H^{\circ}\left(\mathrm{KJ} \mathrm{mol}^{-1}\right)$ & $\Delta G^{\circ}\left(\mathrm{KJ} \mathrm{mol}^{-1}\right)$ & $\Delta S^{\circ}\left(\mathrm{J} \mathrm{K}^{-1} \mathrm{~mol}^{-1}\right)$ & $\Delta H^{\circ}\left(\mathrm{KJ} \mathrm{mol}^{-1}\right)$ \\
\hline 283 & -16.20 & & & -12.04 & & \\
\hline 293 & -20.68 & & & -14.08 & & \\
\hline 303 & -22.51 & 185.88 & 35.81 & -17.80 & 144.58 & 27.95 \\
\hline 323 & -23.75 & & & -18.98 & & \\
\hline 338 & -25.91 & & & -19.86 & & \\
\hline
\end{tabular}



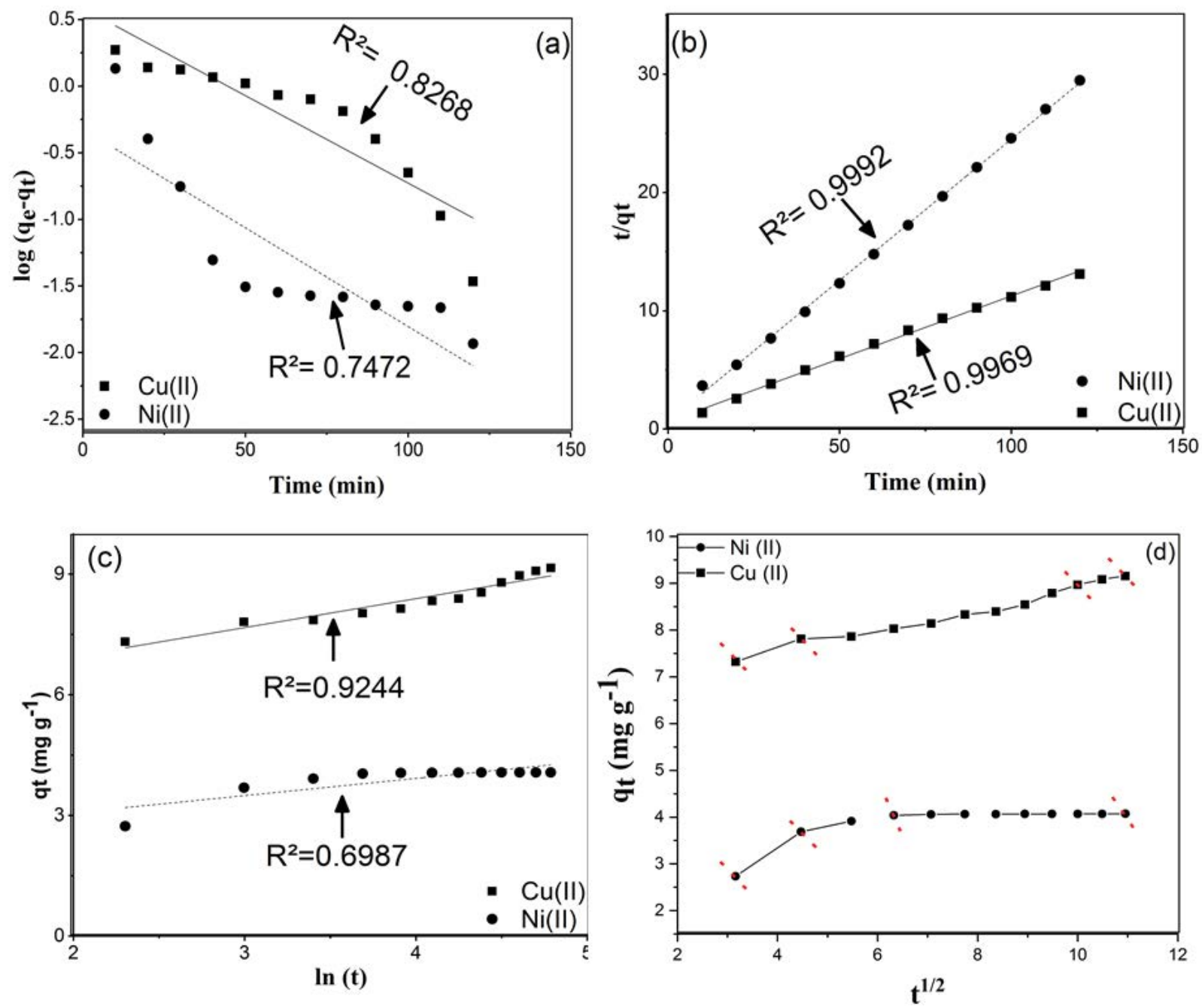

Fig. 6. Kinetics models representation of pseudo-order (a), second-order (b), Elovich (c), and intra-particle (d) for $\mathrm{Cu}(\mathrm{II})$ and Ni(II) adsorption from aqueous solutions onto AO-PANF.

Table 2

Kinetics models constants for $\mathrm{Cu}(\mathrm{II})$ and $\mathrm{Ni}(\mathrm{II})$ removal from aqueous solutions onto AO-PANF

\begin{tabular}{|c|c|c|c|c|c|c|c|c|c|c|c|c|}
\hline & \multicolumn{5}{|c|}{ Pseudo-first-order } & \multicolumn{7}{|c|}{ Pseudo-second-order } \\
\hline & $k_{1}$ & $q_{e, \text { calc }}$ & $R^{2}$ & SD & & $k_{2}$ & $h$ & $q_{e, \text { calc }}$ & & $R^{2}$ & & \\
\hline $\mathrm{Cu}(\mathrm{II})$ & 0.013 & 3.83 & 0.82 & 0.06 & & 0.02 & 1.57 & 9.42 & & 0.99 & & \\
\hline \multirow[t]{3}{*}{$\mathrm{Ni}(\mathrm{II})$} & 0.014 & 0.47 & 0.74 & 1.06 & & 0.75 & 0.37 & 4.18 & & 0.99 & & \\
\hline & \multicolumn{3}{|c|}{ Elovich model } & \multicolumn{9}{|c|}{ Intraparticle diffusion } \\
\hline & $\beta$ & $\alpha$ & $R^{2}$ & $k_{\mathrm{id} 1}$ & $C_{1}$ & $R_{1}^{2}$ & $k_{\mathrm{id} 2}$ & $C_{2}$ & $R_{2}^{2}$ & $k_{\mathrm{id} 3}$ & $C_{3}$ & $R_{3}^{2}$ \\
\hline $\mathrm{Cu}(\mathrm{II})$ & 1.3 & 1,510 & 0.92 & 0.80 & 1.93 & 1 & 0.22 & 6.67 & 0.95 & 0.018 & 8.89 & 0.86 \\
\hline $\mathrm{Ni}(\mathrm{II})$ & 2.3 & 75.5 & 0.69 & 0.72 & 0.43 & 1 & 0.19 & 2.84 & 0.98 & 0.004 & 4.02 & 0.70 \\
\hline
\end{tabular}

The adsorption kinetics of both, $\mathrm{Cu}(\mathrm{II})$ and $\mathrm{Ni}(\mathrm{II})$, are best represented by the pseudo-second-order model, with the highest correlation coefficient values $R^{2}(0.99)$. Therefore, the adsorption of $\mathrm{Cu}(\mathrm{II})$ and $\mathrm{Ni}(\mathrm{II})$ on AO-PANF follow the pseudo-second-order at all times intervals. These data indicate that the chemical sorption took place through chelation interaction involving ion exchange where adsorption capacity is proportional to the number of active sites occupied [36]. The values of $q_{e, \text { xp }}\left(9.19\right.$ and $\left.4.09 \mathrm{mg} \mathrm{g}^{-1}\right)$ and $q_{e, \text { calc }}(9.42$ and $4.18 \mathrm{mg} \mathrm{g}^{-1}$ ) for $\mathrm{Cu}(\mathrm{II})$ and $\mathrm{Ni}(\mathrm{II})$, respectively, are in 
agreement which confirms the validity of pseudo-secondorder model, unlike the pseudo-first-order model where the values are so far and the errors is large. The AO-PANF showed an initial adsorption rate $\left(1.57\right.$ and $0.37 \mathrm{mg} \mathrm{g}^{-1} \mathrm{~min}^{-1}$, respectively) for $\mathrm{Cu}(\mathrm{II})$ and $\mathrm{Ni}(\mathrm{II})$. The comparison of initial adsorption rate values $(\mathrm{h})(1.57$ and 0.37$)$ for $\mathrm{Cu}(\mathrm{II})$ and $\mathrm{Ni}(\mathrm{II})$, respectively, suggested that the adsorption of copper onto AO-PANF is faster than the nickel ions. Additionally, copper present a higher adsorption capacity than nickel.

Concerning the intra-particle diffusion model, the plot of $q_{t}$ vs. $t^{1 / 2}$ illustrated the multi-linearity correlations [37]. For $\mathrm{Cu}(\mathrm{II})$ and $\mathrm{Ni}(\mathrm{II})$ adsorption, three sections were produced for adsorption of $\mathrm{Cu}(\mathrm{II})$ and $\mathrm{Ni}(\mathrm{II})$ onto AO-PANF. The first section represented the instantaneous adsorption, which the heavy metals are attached instantaneously and rapidly from the solution to the AO-PANF surface. The subsequent phase describe the gradual adsorption with a slow rate which can be attributed to the intra-particle diffusion of the metals inside the adsorbent [10]. This decrease can be to the unavailability of active sites in surface of adsorbents [38]. The last section is assigned to the attainment of equilibrium adsorption. The results are in concordance with previous researches $[37,39]$. The intra-particle diffusion constant in every section of the plots follows the order $k_{\mathrm{id} 1}>k_{\mathrm{id} 2}>k_{\mathrm{id} 3}$ demonstrating that adsorption was maximal in the first cycle due to the availability of active sites on the adsorbent surface.

\subsection{Equilibrium adsorption studies}

Adsorption isotherms models were used to correlate the experimental data in order to understand the nature of adsorption of metals toward AO-PANF. In this study, Langmuir, Freundlich, and Dubinin-Radushkevich (D-R) models have been evaluated. The equilibrium adsorption capacity is determined using different concentrations (5-80 $\left.\mathrm{mg} \mathrm{g}^{-1}\right)$ at a constant temperature. The linearized isotherm models are illustrated in Fig. 7 and the calculated parameters are tabulated in Table 3.

The adsorption of $\mathrm{Cu}(\mathrm{II})$ and $\mathrm{Ni}(\mathrm{II})$ onto AO-PANF fit well with the Langmuir equation (Fig. 7a) with a higher regression coefficient $\left(R^{2}=0.9988\right.$ and 0.9852 , respectively)
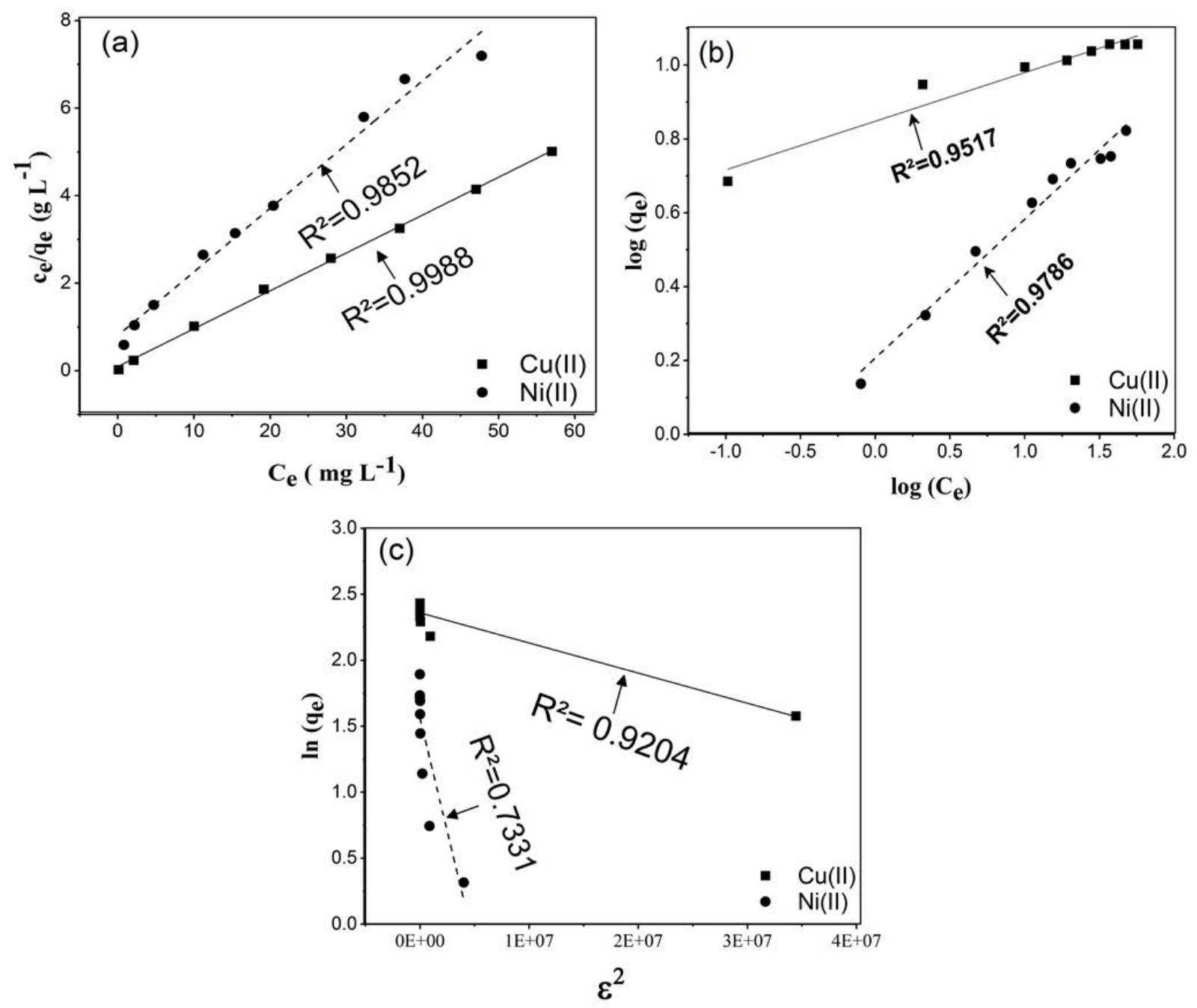

Fig. 7. Isotherm adsorption models representations of Langmuir (a), Freundlich (b), and Dubinin-Radushkevich (c) from aqueous solutions onto AO-PANF. 
Table 3

Isotherms models constants for $\mathrm{Cu}(\mathrm{II})$ and $\mathrm{Ni}(\mathrm{II})$ removal from water by adsorption onto AO-PANF

\begin{tabular}{|c|c|c|c|c|c|c|c|c|c|c|c|c|c|}
\hline & \multicolumn{5}{|c|}{ Langmuir } & \multicolumn{4}{|c|}{ Freundlich } & \multicolumn{4}{|c|}{ Dubinin-Radushkevich } \\
\hline & $K_{L}$ & $R_{L}$ & $q_{m}$ & $R^{2}$ & $\mathrm{RMSD}^{a}$ & $K_{F}$ & $1 / n$ & $R^{2}$ & RMSD & $q_{s}$ & $E$ & $R^{2}$ & RMSD \\
\hline $\mathrm{Cu}(\mathrm{II})$ & 0.9 & 0.1 & 11.56 & 0.99 & 0.04 & 7 & 0.1 & 0.95 & 0.6 & 10.58 & 5 & 0.92 & 0.8 \\
\hline $\mathrm{Ni}(\mathrm{II})$ & 0.2 & 0.3 & 6.87 & 0.98 & 0.1 & 1 & 0.3 & 0.97 & 0.4 & 4.77 & 1.2 & 0.73 & 1.8 \\
\hline
\end{tabular}

${ }^{a}$ root mean standard deviation.

and lower RMSD (0.041 and 0.125, respectively) as shown in Table 3. Therefore, it can be concluded that the distribution of metals onto adsorbent surface is homogeneous and a monolayer is formed [40]. In this study, D-R isotherm model may not be applied for $\mathrm{Ni}(\mathrm{II})$ adsorption onto AO-PANF with a low correlation coefficient $\left(R^{2}=0.7332\right)$ and RMSD (1.88) suggesting that the isotherm models cannot fit with the experimental data. Previous studies have reported that the adsorption of $\mathrm{Cu}(\mathrm{II})$ and $\mathrm{Ni}$ (II) was best described by Langmuir isotherm model [9]. The values of $1 / n$ are less than one indicating a favorable process, also the dimensionless separator factor values $R_{L}$ for $\mathrm{Cu}(\mathrm{II})$ and $\mathrm{Ni}(\mathrm{II})$ adsorption were 0.1 and 0.37 , respectively, confirming that the adsorption is favorable. The values of $K_{L}$ indicate a stronger affinity of adsorbent to $\mathrm{Cu}(\mathrm{II})$ than $\mathrm{Ni}(\mathrm{II})$. The free energy $E$ is $<8 \mathrm{KJ} \mathrm{mol}^{-1}$ demonstrating that the adsorption nature is physique. The maximum adsorption capacity of AO-PANF calculating using Langmuir equation was $11.38 \mathrm{mg} \mathrm{g}^{-1}$ for $\mathrm{Cu}(\mathrm{II})$ and $6.24 \mathrm{mg} \mathrm{g}^{-1}$ for $\mathrm{Ni}(\mathrm{II})$, closer to the experimental values and higher compared to other studies [41]. Finally, the study demonstrates that a quantity of 0.1 and $0.3 \mathrm{~g}$ can effectively remove $\mathrm{Cu}(\mathrm{II})$ and $\mathrm{Ni}(\mathrm{II})$ from aqueous solutions. Moreover, the ability of AO-PANF to remove $\mathrm{Cr}(\mathrm{VI})$ from aqueous solutions was also studied $\left(q_{m}=32.57 \mathrm{mg} \mathrm{g}^{-1}\right)$.

\subsection{Effect of co-existing ions}

Generally, in an industrial wastewater, $\mathrm{Cu}(\mathrm{II})$ and $\mathrm{Ni}(\mathrm{II})$ co-exists with others ions. The effect of co-existing ions present in solutions is an important parameter, which can interfere with the removal of heavy metals. Anions and cations were selected to study the effect of co-existing ions on adsorption capacity of $\mathrm{Cu}(\mathrm{II})$ and $\mathrm{Ni}(\mathrm{II})$. The co-existing ions including chromium $\left(\mathrm{Cr}_{2} \mathrm{O}_{7}^{2-}\right)$, phosphate $\left(\mathrm{PO}_{4}^{2-}\right)$, copper $\left(\mathrm{Cu}^{2+}\right)$, and nickel $\left(\mathrm{Ni}^{2+}\right)$ were separately added to a solution $(50 \mathrm{~mL})$ containing initial concentrations of $30 \mathrm{mg} \mathrm{L}^{-1}$ of either $\mathrm{Cu}(\mathrm{II})$ or $\mathrm{Ni}(\mathrm{II})$ at $\mathrm{pH} 5$ and 7 , respectively, at room temperature (Fig. 8). Different concentrations of co-existing ions were chosen to study the effect.

In a solution containing $\mathrm{Cr}_{2} \mathrm{O}_{7}^{2-}$ no change was observed in the removal of $\mathrm{Cu}(\mathrm{II})$ and $\mathrm{Ni}$ (II) using AO-PANF. For $\mathrm{Ni}$ (II) removal, in the presence of co-existing ions $\left(\mathrm{PO}_{4}^{2-}\right.$, $\mathrm{Cu}^{2+}$, and $\left.\mathrm{SO}_{4}^{2-}\right)$, at low concentrations $\left(20 \mathrm{mg} \mathrm{L}^{-1}\right)$, no obvious change was discovered. Maximal variation was $10 \%$, compared to the adsorption efficiency without co-existing ions, attributed to $\mathrm{PO}_{4}^{2-}$, indicating that they have inconspicuous effect on the adsorption efficiency. Nevertheless, increasing concentration levels of $\mathrm{Cu}$ (II) leads to a significant decrease of the adsorption efficiency of Ni(II). This is due to the competitiveness between $\mathrm{Cu}$ (II) and $\mathrm{Ni}$ (II) and the affinity of AO-PANF toward $\mathrm{Cu}(\mathrm{II})$ [42]. However, the decrease of adsorption efficiency in the presence of $\mathrm{PO}_{4}^{2-}$ and $\mathrm{SO}_{4}^{2-}$ at higher levels can be attributed to the interaction of AO-PANF with anions [43]. For $\mathrm{Cu}(\mathrm{II})$ removal, Co-existing ions $(\mathrm{Ni})$ had no significant change in the adsorption efficiency, which confirms the more affinity of the AO-PANF towards the $\mathrm{Cu}(\mathrm{II})$ than $\mathrm{Ni}(\mathrm{II})$. The removal efficiency decreases from $100 \%$ to $85 \%$ at higher levels of $\mathrm{Ni}(\mathrm{II})$. The
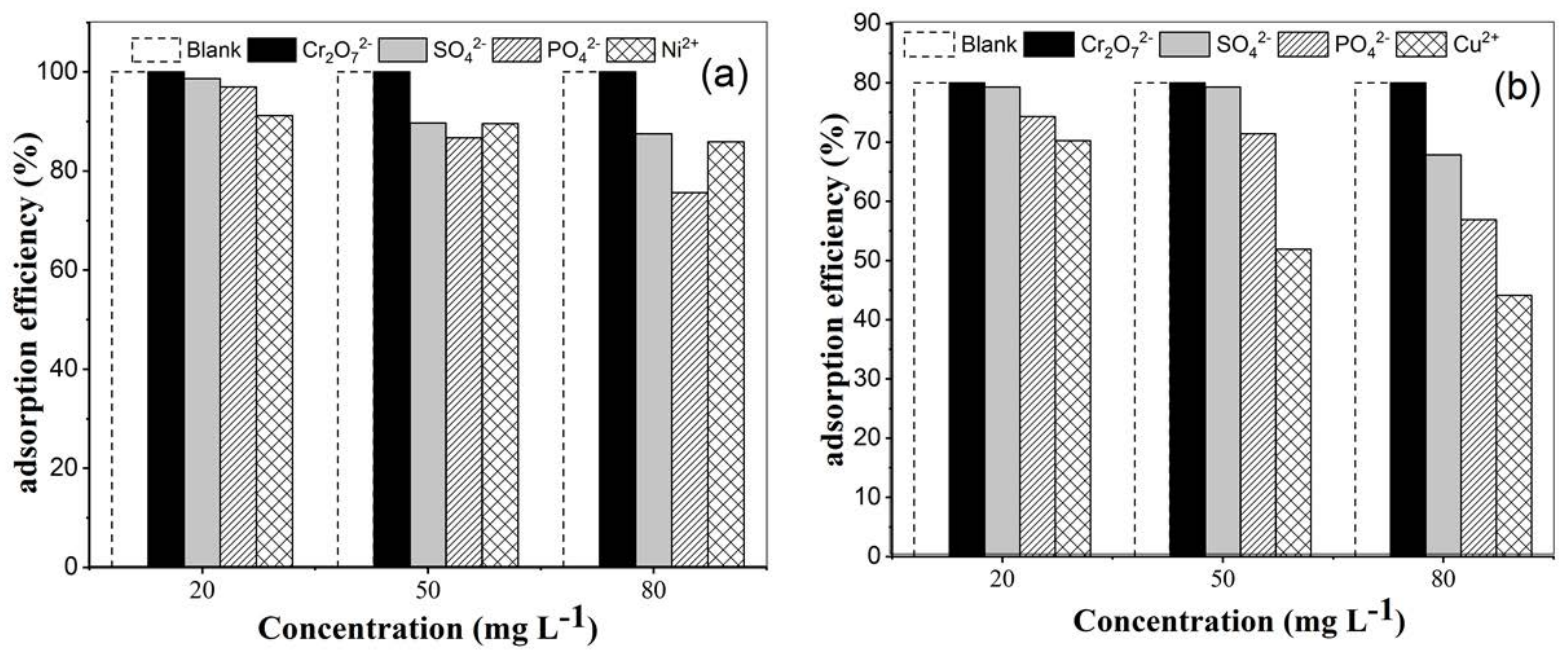

Fig. 8. Effect of co-existing ions on $\mathrm{Cu}(\mathrm{II})$ (a) and $\mathrm{Ni}(\mathrm{II})$ (b) on the adsorption capacity from aqueous solutions. 
same effect of $\mathrm{PO}_{4}^{2-}$ and $\mathrm{SO}_{4}^{2-}$ was noticed with about the same rate decrease. We can conclude that the existence of $\mathrm{PO}_{4}^{2-}$ and $\mathrm{SO}_{4}^{2-}$ has an effect on the adsorption of $\mathrm{Cu}(\mathrm{II})$ and $\mathrm{Ni}(\mathrm{II})$. In addition, the adsorption of $\mathrm{Ni}(\mathrm{II})$ is strongly influenced by the presence of $\mathrm{Cu}(\mathrm{II})$ on solution.

\subsection{Reusability of AO-PANF}

Desorption and regeneration study were carried out using $20 \mathrm{~mL}$ of $0.1 \mathrm{M}$ of $\mathrm{HCl}$ for $1 \mathrm{~h}$ after adsorption of $30 \mathrm{mg} \mathrm{L}^{-1}$ of $\mathrm{Cu}(\mathrm{II})$ and $\mathrm{Ni}(\mathrm{II})$ solutions using $0.2 \mathrm{~g}$ of AO-PANF. The desorption efficiency of $\mathrm{Cu}(\mathrm{II})$ and $\mathrm{Ni}(\mathrm{II})$ using $\mathrm{HCl}$ reached $92 \%$ and $100 \%$, respectively. The desorption efficiency demonstrates that AO-PANF is an effective support for recycling heavy metals from different sources. In fact, according to Table 4, the regenerated AO-PANF could still adsorb $\mathrm{Cu}(\mathrm{II})$ and $\mathrm{Ni}(\mathrm{II})$ from aqueous solutions after three adsorption-desorption cycles.

Thus, the adsorption efficiency of AO-PANF gradually decreases to $70 \%$ and $51 \%$ of the original adsorption efficiency, respectively but still applicable in heavy metal removal. This decrease is may be due to the destruction of functional groups during the adsorption-desorption experiments in acidic solutions. This results has also been observed by others researchers $[44,45]$.

\section{Conclusion}

Amidoximated polyacrylonitrile fibers (AO-PANF) were synthesized by using hydroxylamine hydrochloride. The resulting AO-PANF adsorbent has demonstrated its capacity for removing copper and nickel ions from aqueous solutions. Moreover, the copper and nickel ions removals from water were found to depend on various adsorption parameters such as the aqueous phase $\mathrm{pH}$, the contact time, the adsorbent dose the temperature, and the presence of co-existing ions in solution. The optimal $\mathrm{pH}$ values of copper and nickel removal from water were evaluated and were, respectively, $\mathrm{pH}=5$ and 7 .

A good agreement was found between the experimental adsorption data and the Langmuir theoretical predictions, whereas the kinetics results were found to follow the pseudosecond-order. The maximum adsorption capacity for $\mathrm{Cu}(\mathrm{II})$ and $\mathrm{Ni}(\mathrm{II})$ using AO-PANF were, respectively, 11.38 and $6.24 \mathrm{mg} \mathrm{g}^{-1}$. At the equilibrium, the adsorbed amounts were obtained at 90 and $30 \mathrm{~min}$, for $\mathrm{Cu}(\mathrm{II})$ and $\mathrm{Ni}(\mathrm{II})$, respectively. In addition, the endothermic and the spontaneous nature of the adsorption reaction were evidenced from the thermodynamics studies. The adsorption experiments were found to be efficient at room temperature. Finally, the presence of the co-existing ions in the aqueous solution was found

Table 4

Regeneration efficiency of AO-PANF

\begin{tabular}{lllll}
\hline \multirow{2}{*}{ Metals } & \multicolumn{4}{c}{ Adsorption efficiency (\%) } \\
\cline { 2 - 5 } & Cycle 1 & Cycle 2 & Cycle 3 & Cycle 4 \\
\hline $\mathrm{Cu}(\mathrm{II})$ & 100 & 100 & 86 & 70 \\
$\mathrm{Ni}(\mathrm{II})$ & 92 & 90 & 78 & 51 \\
\hline
\end{tabular}

to decrease the adsorption efficiency of these metals. The reuse of AO-PANF was found to be possible for three cycles of adsorption-desorption. The Overall data indicate that the AO-PANF can be used as adsorbent to remove, efficiently, the $\mathrm{Cu}(\mathrm{II})$ and $\mathrm{Ni}(\mathrm{II})$ from aqueous solutions.

\section{Acknowledgments}

The authors would like to thank the supervisory Board of Higher School of Textile and Clothing Industries (ESITH) for financial support and technical assistance and the faculty of science Ain Chok.

\section{Symbols}

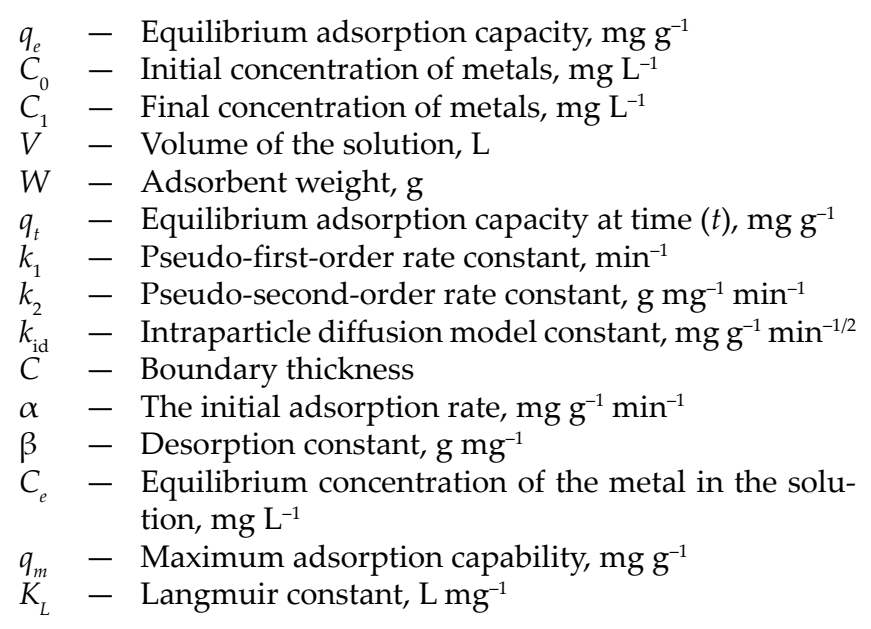

\section{References}

[1] S.V. Mousavi, A. Bozorgian, N. Mokhtari, M.A. Gabris, H.R. Nodeh, W.A.W. Ibrahim, A novel cyanopropylsilanefunctionalized titanium oxide magnetic nanoparticle for the adsorption of nickel and lead ions from industrial wastewater: equilibrium, kinetic and thermodynamic studies, Microchem. J., 145 (2019) 914-920.

[2] Jumina, Y. Priastomo, H.R. Setiawan, Mutmainah, Y.S. Kurniawan, K. Ohto, Simultaneous removal of lead(II), chromium(III), and copper(II) heavy metal ions through an adsorption process using C-phenylcalix [4] pyrogallolarene Material, J. Environ. Chem. Eng., 8 (2020) 103971.

[3] S. He, Y. Li, L. Weng, J. Wang, J. He, Y. Liu, K. Zhang, Q. Wu, Y. Zhang, Z. Zhang, Competitive adsorption of $\mathrm{Cd}^{2+}, \mathrm{Pb}^{2+}$ and $\mathrm{Ni}^{2+}$ onto $\mathrm{Fe}^{3+}$-modified argillaceous limestone: influence of $\mathrm{pH}$, ionic strength and natural organic matters, Sci. Total Environ., 637 (2018) 69-78

[4] E. Torrik, M. Soleimani, M.T. Ravanchi, Application of kinetic models for heavy metal adsorption in the single and multicomponent adsorption system, Int. J. Environ. Res., 13 (2019) 813-828.

[5] Y. Deng, S. Huang, D.A. Laird, X. Wang, Z. Meng, Adsorption behaviour and mechanisms of cadmium and nickel on rice straw biochars in single-and binary-metal systems, Chemosphere, 218 (2019) 308-318.

[6] X. Xie, R. Deng, Y. Pang, Y. Bai, W. Zheng, Y. Zhou, Adsorption of copper(II) by sulfur microparticles, Chem. Eng. J., 314 (2017) 434-442.

[7] D. Liu, Y. Tao, K. Li, J. Yu, Influence of the presence of three typical surfactants on the adsorption of nickel(II) to aerobic activated sludge, Bioresour. Technol., 126 (2012) 56-63.

[8] J. Liu, C. Wang, Z. Xiong, Adsorption behavior of magnetic multiwalled carbon nanotubes for the simultaneous adsorption 
of furazolidone and $\mathrm{Cu}(\mathrm{II})$ from aqueous solutions, Environ. Eng. Sci., 32 (2015) 960-969.

[9] H. Demiral, C. Güngör, Adsorption of copper(II) from aqueous solutions on activated carbon prepared from grape bagasse, J. Cleaner Prod., 124 (2016) 103-113.

[10] A. Labidi, A.M. Salaberria, S.C. Fernandes, J. Labidi, M. Abderrabba, Adsorption of copper on chitin-based materials: kinetic and thermodynamic studies, J. Taiwan Inst. Chem. Eng., 65 (2016) 140-148.

[11] İ. Kara, D. Yilmazer, S.T. Akar, Metakaolin based geopolymer as an effective adsorbent for adsorption of zinc(II) and nickel(II) ions from aqueous solutions, Appl. Clay Sci., 139 (2017) 54-63.

[12] R. Shan, Y. Shi, J. Gu, Y. Wang, H. Yuan, Single and competitive adsorption affinity of heavy metals toward peanut shell-derived biochar and its mechanisms in aqueous systems, Chin. J. Chem. Eng., 28 (2020) 1375-1383.

[13] A.D. Delil, O. Gülçiçek, N. Gören, Optimization of adsorption for the removal of cadmium from aqueous solution using Turkish coffee grounds, Int. J. Environ. Res., 13 (2019) 861-878.

[14] C.-Z. Zhang, Y. Yuan, T. Li, Adsorption and desorption of heavy metals from water using aminoethyl reduced graphene oxide, Environ. Eng. Sci., 35 (2018) 978-987.

[15] J. Dong, Y. Du, R. Duyu, Y. Shang, S. Zhang, R. Han, Adsorption of copper ion from solution by polyethylenimine modified wheat straw, Bioresour. Technol. Rep., 6 (2019) 96-102.

[16] H.-P. Chao, C.-C. Chang, Adsorption of copper(II), cadmium(II), nickel(II) and lead(II) from aqueous solution using biosorbents, Adsorption, 18 (2012) 395-401.

[17] X. Wang, X. Liang, Y. Wang, X. Wang, M. Liu, D. Yin, S. Xia, J. Zhao, Y. Zhang, Adsorption of copper(II) onto activated carbons from sewage sludge by microwave-induced phosphoric acid and zinc chloride activation, Desalination, 278 (2011) 231-237.

[18] G. Ndayambaje, K. Laatikainen, M. Laatikainen, E. Beukes, O. Fatoba, N. van der Walt, L. Petrik, T. Sainio, Adsorption of nickel(II) on polyacrylonitrile nanofiber modified with 2-(2'-pyridyl) imidazole, Chem. Eng. J., 284 (2016) 1106-1116.

[19] C. Jianfui, M.S. Sarjadi, B. Musta, M.S. Sarkar, M.L. Rahman, Synthesis of sawdust-based poly(amidoxime) ligand for heavy metals removal from wastewater, ChemistrySelect, 4 (2019) 2991-3001.

[20] M. Abdouss, M. Shoushtari, A. Haji, B. Moshref, Fabrication of chelating diethylenetriaminated pan micro and nano fibers for heavy metal removal, Chem. Ind. Chem. Eng. Q., 18 (2012) $27-34$.

[21] M. Soltanzadeh, G. Kiani, A. Khataee, Adsorptive capacity of polyacrylonitrile modified with triethylenetetramine for removal of copper and cadmium ions from aqueous solutions, Environ. Prog. Sustainable Energy, 33 (2014) 1139-1147.

[22] X. Zhang, X. Peng, T. Yang, H. Zou, M. Liang, G. Shi, W. Yan, Amidoximation of cross-linked polyacrylonitrile fiber and its highly selective gallium recovery from Bayer liquor, Polym. Bull., 76 (2019) 4189-4204.

[23] L. Zeng, Q. Liu, M. Lu, E. Liang, G. Wang, W. Xu, Modified natural loofah sponge as an effective heavy metal ion adsorbent: amidoxime functionalized poly(acrylonitrile-g-loofah), Chem. Eng. Res. Des., 150 (2019) 26-32.

[24] M. Avila, T. Burks, F. Akhtar, M. Göthelid, P.C. Lansåker, M.S. Toprak, M. Muhammed, A. Uheida, Surface functionalized nanofibers for the removal of chromium(VI) from aqueous solutions, Chem. Eng. J., 245 (2014) 201-209.

[25] H. Bouchoum, D. Benmoussa, A. Jada, M. Tahiri, O. Cherkaoui, Synthesis of amidoximated polyacrylonitrile fibers and its use as adsorbent for $\mathrm{Cr}(\mathrm{VI})$ ions removal from aqueous solutions, Environ. Prog. Sustainable Energy, 38 (2019) 13196.

[26] S.O. Adio, M. Asif, A.-R.I. Mohammed, N. Baig, A.A. Al-Arfaj, T.A. Saleh, Poly(amidoxime) modified magnetic activated carbon for chromium and thallium adsorption: statistical analysis and regeneration, Process Saf. Environ. Prot., 121 (2019) 254-262.
[27] H.A. Flaschka, EDTA Titrations: An Introduction to Theory and Practice, Elsevier, Amsterdam, Netherlands, 2013.

[28] J. Mendham, Analyse Chimique Quantitative de Vogel, De Boeck Supérieur, Paris, France, 2005.

[29] J. Zhai, E. Bakker, Complexometric titrations: new reagents and concepts to overcome old limitations, Analyst, 141 (2016) 4252-4261.

[30] M. Neelaveni, P.S. Krishnan, R. Ramya, G.S. Theres, K. Shanthi, Montmorillonite/graphene oxide nanocomposite as superior adsorbent for the adsorption of Rhodamine B and Nickel ion in binary system, Adv. Powder Technol., 30 (2019) 596-609.

[31] M. El Bouchti, A. Grancaric, L. Botteri, H. Hannache, $\mathrm{O}$. Cherkaoui, Removal of $\mathrm{Pb}^{2+}$ and $\mathrm{Cu}^{2+}$ from their aqueous solutions by functionalized polyamide 6.6 yarns with $\mathrm{N}$-allyliminodiacetic acid, J. Mater. Environ. Sci., 6 (2014) $146-154$.

[32] X.-s. Wang, Y. Qin, Equilibrium sorption isotherms for of $\mathrm{Cu}^{2+}$ on rice bran, Process Biochem., 40 (2005) 677-680.

[33] Q. An, Y.-Q. Jiang, H.-Y. Nan, Y. Yu, J.-N. Jiang, Unraveling sorption of nickel from aqueous solution by $\mathrm{KMnO}_{4}$ and KOH-modified peanut shell biochar: implicit mechanism, Chemosphere, 214 (2019) 846-854.

[34] D. Jiang, Y. Yang, C. Huang, M. Huang, J. Chen, T. Rao, X. Ran, Removal of the heavy metal ion nickel(II) via an adsorption method using flower globular magnesium hydroxide, J. Hazard. Mater., 373 (2019) 131-140.

[35] R.J. Kongarapu, A.K. Nayak, M.U. Khobragade, A. Pal, Surfactant bilayer on chitosan bead surface for enhanced Ni(II) adsorption, Sustainable Mater. Technol., 18 (2018) e00077 1-10.

[36] R.L. White, C.M. White, H. Turgut, A. Massoud, Z.R. Tian, Comparative studies on copper adsorption by graphene oxide and functionalized graphene oxide nanoparticles, J. Taiwan Inst. Chem. Eng., 85 (2018) 18-28.

[37] K. Naseem, R. Begum, W. Wu, M. Usman, A. Irfan, A.G. Al-Sehemi, Z.H. Farooqi, Adsorptive removal of heavy metal ions using polystyrene-poly (N-isopropylmethacrylamide-acrylic acid) core/shell gel particles: adsorption isotherms and kinetic study, J. Mol. Liq., 277 (2019) 522-531.

[38] A.M. Atta, H.A. Al-Lohedan, Z. ALOthman, A.A. AbdelKhalek, A.M. Tawfeek, Characterization of reactive amphiphilic montmorillonite nanogels and its application for removal of toxic cationic dye and heavy metals water pollutants, J. Ind. Eng. Chem., 31 (2015) 374-384.

[39] Y. Huang, H. Wu, T. Shao, X. Zhao, H. Peng, Y. Gong, H. Wan, Enhanced copper adsorption by DTPA-chitosan/alginate composite beads: mechanism and application in simulated electroplating wastewater, Chem. Eng. J., 339 (2018) 322-333.

[40] K. Tohdee, L. Kaewsichan, Enhancement of adsorption efficiency of heavy metal $\mathrm{Cu}$ (II) and $\mathrm{Zn}$ (II) onto cationic surfactant modified bentonite, J. Environ. Chem. Eng., 6 (2018) 2821-2828.

[41] T. Aman, A.A. Kazi, M.U. Sabri, Q. Bano, Potato peels as solid waste for the removal of heavy metal copper(II) from waste water/industrial effluent, Colloids Surf., B, 63 (2008) 116-121.

[42] Z. Liu, X. Li, P. Zhan, F. Hu, X. Ye, Removal of cadmium and copper from water by a magnetic adsorbent of PFM: adsorption performance and micro-structural morphology, Sep. Purif. Technol., 206 (2018) 199-207.

[43] L. Fan, C. Luo, M. Sun, X. Li, H. Qiu, Highly selective adsorption of lead ions by water-dispersible magnetic chitosan/graphene oxide composites, Colloids Surf., B, 103 (2013) 523-529.

[44] C. Chen, F. Li, Z. Guo, X. Qu, J. Wang, J. Zhang, Preparation and performance of aminated polyacrylonitrile nanofibers for highly efficient copper ion removal, Colloids Surf., A, 568 (2019) 334-344.

[45] P. Bhunia, S. Chatterjee, P. Rudra, S. De, Chelating polyacrylonitrile beads for removal of lead and cadmium from wastewater, Sep. Purif. Technol., 193 (2018) 202-213. 